\title{
The Role of the cooperation of tourist actors in cluster form in the attractiveness of territories: A qualitative study of Tangier city
}

\author{
Brahim BENBBA ${ }^{1}$, Younes OUBAIH ${ }^{2}$
}

Marketing, Logistics and Management Laboratory, National School of Commerce and Management ENCG, Tangier, Morocco.

\begin{abstract}
In this paper we seek to study the nature of the relationship between tourism cooperation in the form of a cluster and the tourist attractiveness of their territories through, first, the presentation of a literature review that deals with the different facets of this issue and, secondly, through a qualitative exploratory study of tourism actors in the city of Tangier in order to assess the actors' perception on the role that cluster-based networking could play in the development of the tourist attractiveness of Tangier city.
\end{abstract}

Key words: cluster, tourism, cooperation, actors, territory, attractiveness

\section{Introduction}

The attractiveness of places depends largely - even if not exclusively - on the quantity and quality of their resources, which is an essential precondition for their tourist development. Nevertheless, there is growing recognition that the resource or the endowment is not sufficient: an increasing number of destinations are adopting sophisticated strategies to attract visitors, beyond traditional promotional activities. Growing environmental concerns, social instability, the rapid growth of new technologies and the pressing need for security all pose threats and opportunities for destinations and industries (Gibson, Pennington-Gray \& Thapa 2003).

Competition between and within destinations has become fierce and the tourism market is constantly changing. New destinations are entering the market and new strategic alliances are forming. Tourism demand is also changing: tourists are better informed about products and services, and they emphasize lowcost offers and quality experiences. As a result, some destinations are suffering, despite the growth of the global tourism market and their potential endowment of attractive resources (UNWTO, 2011).

Moreover, it is recognized that, even if competition is exercised at all geographical scales, the local level is the most relevant: competitive pressure requires local governments and policy makers to re-evaluate the use made of their tourism resources for capitalize on them and increase the performance of tourist destinations. In particular, community-based approaches and theories of clusters, districts, and local cooperation are gaining increasing attention from academics and practitioners (Antonioli 1999, Milne and Ateljevic 2001). The tourism cluster is one facet of this cooperation. Very widespread and often studied at the industrial level (Marshall, Beccatini, Porter), clusters (or clusters of companies) are still little developed in the tourism sector.

The literature review on tourism clusters clearly shows the difficulties that researchers have encountered in moving the concept from the industry sector where it was first created to the tourism sector. The specificities of the tourism sector have prevented researchers from analyzing and encircling the concept of tourism cluster from all angles, with works that complements each other and treats the concept according to different approaches and contexts. Implicitly or explicitly, they marked the strong relationship between cooperated work of tourism actors in the form of tourism cluster on one hand and the tourist attractiveness of their territory on the other hand. 
This paper is an opportunity to present a synthesis of an emerging literature that discusses the important role played by tourism cluster in the tourist attractiveness of the territories. So, an analysis will be extended through a qualitative-exploratory study of tourism stakeholders in Tangier.

\section{Review of Literature}

Tourism companies are concerned by the issue of networking, creating specific and inimitable resources. The quality of the coordination between the actors in charge of the production and the commercialization of the tourist stay constitutes a strong stake of the competitiveness of the destinations (Bocquet 2008).

The origins of the cluster concept go back a long way, especially to 1890 with the beginning of work in the industrial sector of the dominant figure of the British economy Alfred Marshall. The latter has indeed developed the theory of industrial agglomeration which has given emergence the studies on external effects and manufacturing districts.

Alfred Marshall defined industrial districts as a group of interdependent enterprises that come together around a specialized labor market in a limited geographical space, thus, highlighting the fundamental role of the territory in industrial organization and the existence of its external savings effects generated by the industrial district. These external economies provide a set of benefits to the district's integrated enterprises (i.e., reductions in production and transaction costs, osmosis and the sharing of skills and resources based on trust and fostered by proximity).

In the 1990s, Michael Porter paid tribute to the long-ignored works of Alfred Marshall and introduced the notion of cluster and the advantages of concentration of activities on a territory. Porter (1990) defines the cluster as "a geographically close group of related enterprises and associated institutions within a given domain, between which there are common elements and complementarities. Its geographical extent varies from a single city or region to an entire country, or even to a network of neighboring countries [...] ".

Thus, the cluster according to Porter is synonymous with the grouping of actors (public, private and institutional) geographically and economically, reinforced by strong interactions between actors linked by the same activity and common or complementary objectives.

Several other definitions of the cluster concept followed Porter's; they are heterogeneous definitions with common attributes:

$\neg$ Clusters are groups of companies and institutions (research centers, training centers, universities, etc.) linked by a dominant activity in a specific territory;

$\neg$ The companies come from the same sector or from a complementary sector. They can share the same area of expertise;

$\neg$ The actors maintain vertical relationships (between economic sectors and scientific research) or horizontal relations (within the same sector);

$\neg$ Geographical proximity has positive effects linked to access to specific tangible and intangible resources, but also to fundamental skills.

The cluster concept has subsequently been adopted and adapted in several other sectors, including the tourism sector, a sector that has its own specificities and that engages a number of heterogeneous actors, who participate directly, indirectly or even induced in in the tourist activities of a territory.

The tourism cluster is the networking of all the stakeholders of tourism of a territory. In other words, the tourism cluster is the organization of all stakeholders of tourism of a given territory around a clear structure and where each stakeholder is familiar with its role, rights and obligations. Cooperation that is vertical and / or horizontal while giving the notion of competition a sense of coordination. "The cluster adds value to the initial location (resources / endowments) and makes the actors more cooperative and interactive. It helps the 
destination, understood as an innovative economic system, to move from the notion of tourist area to that of tourist destination, which reinforces the attractiveness of the destination. "(Fabry Nathalie, Zeghni Sylvain 2012).

According to Elise Durey (2016), the tourism cluster "concentrates, at the scale of a tourist destination, on the companies and actors of different tourist sectors (hosts, providers of animation of stays, sites and museums, carriers, receptive agencies, agents of marketing and territorial reception, cultural actors ...). Together, they agree on a common strategic vision to raise the stakes and develop the competitiveness of the tourism of their territory".

The transfer of the concept of the industrial sector to that of tourism is not an easy task neither for the researchers nor for the practitioners. Because of the heterogeneity of the actors of tourism and the divergence of their interests, one must also take into account the complexity of the meaning of the tourist product: a product that is not mobile and requires to be consumed in situ by the tourist who, himself, engages in voluntary mobility; the tourist becomes, whenever he buys a service, co-producer of the tourist service. Contrary to the industrial logic, the place of consumption is different from the place of residence of the consumer (tourist). Tourism stakeholders must therefore be close to the tourist attraction. "The tourism cluster, for its part, is based on a very strong specificity related to the nature of the tourism sector and that of the tourist product which is a product of assembly where the tourist is a co-producer but not a resident" (Fabry Nathalie, Zeghni Sylvain 2012).

The literature review on tourism clusters confirms and explains the difficulties that researchers have encountered in moving the concept of the industry sector -where it was first created- to the tourism sector, particularly with more and more works today that deal with different facets of this transfer from which we can mention the following: The comparison between destination and district by Anne-Mette Hjalager (2000), the projection and analysis of the concept of the tourism cluster in specific territories according to different contexts with the work of Ewen Michael (2003) on the case of tourism micro-cluster in Australia, the work that sought to analyze the existing tourism clusters, following territorial policies initiated by governments or by professionals of tourism with the work of Marie Eve Férérol (2013) on the case of the tourism cluster Goazen in the Basque country and the work of Nathalie Fabry (2013) on the Val d'Europe tourism cluster case other works have tried to approach the concept in a theoretical framework, like those of Philippe Violier (2014) and Cécile Clergeau (2016).

The specificities of tourism sector have prevented researchers from analyzing and delineating the concept of the tourism cluster from all angles with complementary work that addresses the concept in different approaches and contexts, that have implicitly or explicitly stated that the tourism cluster is a powerful tool for tourism development based on sustainability, innovation and governance. Researchers have unanimously affirmed that the tourism cluster is a relevant tool for developing the tourist attractiveness of the territories.

\subsection{The role of tourism clusters}

On the basis of the literature review on tourism clusters, we have been able to identify three dimensions on which a tourism cluster builds in order to achieve its role as a performance tool for a better tourist attraction of the territories, namely: The dimension related to governance, the dimension of innovation and the dimension of sustainable development.

\subsubsection{The dimension related to innovation}

According to Albrecht, (2013) "The collaboration of the different actors in the field of tourism, in particular within networks of actors, is identified as an important lever in the field of innovation". There is an emerging literature that has looked at the opportunities offered by the cluster to promote innovation (Weidenfield et al., 2010, 2011, Nordin, 2003, Novelli et al., 2006). This is also accompanied by the natural evolution of the cluster concept itself, where the initial focus has been on the benefits of agglomeration economies with respect to a more dynamic and systemic approach that emphasizes adaptation and innovation as a critical mechanism (Cruz et al, 2010).

In addition, this is linked to the growing application by many countries of policies emphasizing the benefits of a collaborative exchange between different agents (companies, universities and governments) to obtain 
benefits from the execution of innovative joint projects. This applies quite well to the tourism sector, characterized by an overview of atomized SMEs and where the cluster could be a means to mitigate the consequences of market inefficiencies related to the size and coordination of the business that affect the markets. Business-to-business relationships, thereby increasing knowledge flows and reaching a critical mass that facilitates innovation. Regarding the positive relationship between clusters and innovation, Bell (2005) states that clustered companies have better access to information and that members have common knowledge because of their proximity. Direct observation of competitors is an imitation that could mutate and drift into innovation. Bathelt et al. (2004) focus on the forms of knowledge (tacit and codified) that coexist in a cluster and come from both inside and outside. Both forms offer benefits to the innovation process.

Other international cluster development experiences (in Australia, California, South Africa, and Are's Swedish tourism destination) were analyzed by Nordin (2003) in order to bridge the link between the tourism cluster concept and innovation. Other works explore the relationship between clusters and local tourism innovation systems (Prats \& Guía 2008) and in addition to the concept of governance (Svensson et al. 2005).

\subsubsection{The governance dimension}

According to Fabry Nathalie and Zeghni Sylvain, (2012) "The tourism cluster calls for the choice of a flexible mixed governance where the stakeholders impose themselves and fade according to the context. It is a question of wondering if at each stage of its evolution, the cluster is endowed with the corresponding governance ".

The cluster is also a governance structure, because within a tourism cluster, governance implies that actors determine, implement and evaluate the rules of their interactions (Beritelli, Bieger and Laesser 2007).

The concept of governance leads us to distinguish two types of inter-organizational relations: A first type of relationship concerns cooperation links and a second type of relationship that supports the coordination of collective actions. For Chabault (2007), "it is necessary to organize inter-organizational relations and coordinate the activities of heterogeneous actors, whose logic of actions and systems of representation differ from each other". The heterogeneity of the actors and the divergence of their interests refer to the setting up of a governance structure to coordinate the collective action (Provan and Kenis 2008). Mendez and Messeghem (2009) argue that "the linking and development of effective and truly productive cooperation between such different actors can not be decreed". Partnerships require institutional support to align objectives and create common benchmarks, in other words, to go beyond geographical proximity, and to develop institutional proximity, that is, to share a set of representations (Bellet, Colletis and Lung 1993). In addition, territorial action does not spontaneously emerge a network and reinforces the need for a governance structure (Gomez 2009). The cluster therefore necessarily needs cooperation and also coordination between the organizations. For Porter (1990b), a cluster is vulnerable when a large number of firms within it do not have a global strategy.

\subsubsection{The dimension related to sustainable development}

According to Elise Durey (2016) "The cluster is a useful tool to sustainably establish the tourist attractiveness of a destination". The interaction of consumption of the tourist product with the visited territory is one of the main characteristics of the tourist activity, showing the fundamental role that it plays in the strategies of local development. In most economic activities, it is the product that moves towards the consumer, but in tourism, it is the opposite. Because of this characteristic, tourism has a significant impact on local development. In this perspective, tourism and local development are interconnected because they take place in regions, and socio-cultural and environmental characteristics must be respected during the course of the tourism activity.

The central idea of development comprises a concept composed of evolution, inclusion, participation, solidarity, production and competitiveness, mutually reinforced or directly opposed to the movements of concentration, competition, exclusion, poverty and imbalance. Evolution and interaction are the focal points of the concept of development, a set of coordinated participatory processes to further improve the discussion 
and increase of the planning capacity and the ability to collect economic, social and environmental resources in the short and long term, as far as possible because of joint strategies that are otherwise dependent on arbitration and conciliation (OECD 2001).

The concept of local development also includes complementary ideas related to the territory. One of them refers to a concrete and delimited space, which is linked to the idea of constancy and inertia, and can be identified as a limited area such as a municipality, a micro-region, etc. The other is the abstract space of social relations and indicates the movement and interaction between social groups that cooperate or organize an opposition to take into account their common interests (Fischer 2002). The idea of movement and interaction can be observed as long as the territory has to take into account the interdependence between nature and its use, including human actions, namely work and politics (Santos 1999).

Three elements of local development derived from tourism are: society, the environment and the economy, which are integrated and mutually reinforced in a context where social and cultural diversity, as well as productive differences, should be used as resources to generate changes geared towards sustainable development.

The cluster mission included in the strategy promotes socio-economic development in local territories by improving activities in the tourism sector. This is possible by applying the principles of sustainable development to all levels of cluster operation, as it brings together leading tourism businesses and other organizations working closely with the tourism sector. The actions on sustainable development confirm the validity of efforts to make the destination suitable for residents, tourists and entrepreneurs, this idea will link efforts to create a balance between the environmental, social and economic aspects of regional development. Much more effort is needed to gain knowledge about sustainable development among entrepreneurs and the local community before actions in this direction are taken (Porter 1998).

The most important benefits of clustering cluster tourism actors are as follows:

- Acquiring new customers because of the green trend of the industry by creating green labels / labels to stand out;

- Simpler foundation if the principles of sustainable development are applied in the Business Strategy;

- Reduce the cost of doing business by improving efficiency;

- Encourage qualified employees to join companies as they become more attractive;

- Better competitiveness and quality in tourism products / services;

- Long-term development of the region;

- More advanced technologies.

\section{Methodology}

In order to better understand the contributions of the tourism cluster for a better tourist attraction of a territory, an exploratory qualitative study was carried out.

Of the five qualitative methods presented by Creswell (2006), (Narrative Ethnography, Phenomenology, Grounded Theory, Case Study), we have opted for the case study method that Yin (2003) defines as "an empirical investigation that studies a contemporary phenomenon in its real-life context, especially when the boundaries between the phenomenon and the context are not clearly defined", which offers a variety of participants' points of view, and uses multiple data collection techniques.

In order to cover the heterogeneity and variability of concepts related to the issue of cooperation between tourism stakeholders, our choice was based on a case study: "exploratory" (Yin 1984), "synchronic" (Grenier and Josserand 1999), and "multiple" (Yin 1984). 
Individual semi-structured interviews, lasting from 30 to 45 minutes, were carried out using an interview guide (inspired by the literature review we consulted) with fifteen tourism stakeholders installed in the city of Tangier, Morocco, (the theoretical saturation threshold was reached at the level of thirteen actors, two actors were added in order to confirm that the theoretical saturation was reached), a sampling according to the rich case method in information has been mobilized, Patton (2002) "Information-rich cases are those from which much can be learned about issues of central importance to the purpose of the research." The interviews were supplemented by non-participant direct observation, which is considered relevant because the data it generates makes it possible to verify the validity of the data collected during the interviews and to update them (Yin 2003).

The interview guide, formulated by open questions, which evolves from one interview to another, aims to detect the perception of stakeholders interviewed on the role that cluster networking could play in attractiveness of their destination.

The interviewees freely expressed their opinions. Each interview was recorded using a dictaphone, and the data collected were fully transcribed for analysis.

Thanks to the qualitative data analysis software NVIVO11, which we considered to be adapted to our case, the key factors and dimensions of coordination between tourism stakeholders were defined as well as their contribution to the tourist attractiveness of the city of Tangier, by means of a textual and semantic analysis. In the first step, we performed a lexical analysis. This shows the nature and richness of the vocabulary used by the tourism stakeholders interviewed. We thus calculated the occurrence of the keywords of the corpus.

In the second step, we coded by defining the variables and the different themes. This codification was inspired by the theoretical framework. Finally, we did a content analysis.

\section{Results}

The results of the lexical analysis highlight the importance attributed by actors to certain words and themes. All of the identified keywords have been grouped into lexical universes on the basis of belonging to common categories. Analysis and discussion of the results of the interviews will allow us to explore the nature of the factors and dimensions of the cluster and their contributions to tourism attractiveness. The conclusions of the analysis will lead to the proposal of a conceptual model.

\subsection{Presentation and analysis of the main results}

The tourism stakeholders interviewed say that networking in the form of a cluster would be a solution of choice to remedy the anarchy that the tourism sector lives in (work isolated from the actors) and would thus develop the tourist attractiveness of the city of Tangier, according to private_actor_5 "Attractiveness is the fact of attracting the tourist, of course, but also of pushing him/er to return again and again, through quality tourist services, the tourism cluster will certainly be a tool to check its two levels of tourist attractiveness". The cluster according to Michael, (2003) is a producer of "meaning" for the actors in place and offers a framework of analysis to understand the dynamics of territories with a tourist vocation.

Thus we affirm that the tourist actors of the city of Tangier perfectly understand the role that could play a cluster of tourism in their cooperation and also in the revitalization of their interactions in favor of the attractiveness of their destination "The cluster adds the value at the initial location (resources/endowments) and makes the actors more cooperative and interactive. It helps the destination, understood as an innovative economic system, to move from the notion of tourist area to that of tourist destination, which reinforces the attractiveness of the destination. "(Fabry Nathalie, Zeghni Sylvain 2012).

To reach the real tourist attractiveness of the city of Tangier based on a dynamic and sustainable approach, tourism stakeholders interviewed admit unanimously that the tourism cluster should be able to create:

- An environment conducive to innovation that Giacomo Becattini described as a creative environment in 1977 and an innovative environment by Aydalot in 1984. The tourism stakeholders interviewed shed light on the fact that the tourism cluster would play the role of a relevant tool at the level of : 
$\checkmark$ The continuous training of tourism professionals in the city, quality training in line with the perspective of the strategy drawn;

$\checkmark$ Active technology watch to keep up to date with what is happening outside the city and even the country in terms of technological tools and solutions related to tourism activity;

$\checkmark$ Smooth knowledge transfer between actors, according to Sorensen, (2007) tourism cluster argued that knowledge transfer was more important than proximity relations with employees of other institutions of the same tourist destination, Shaw and Williams (2009) considered tourism clusters as vehicles for tacit knowledge transfer, arguing that proximity facilitated trust and shared values for effective knowledge sharing through inter-firm linkages and informal individual relationships;

$\checkmark$ And the ability to adapt to new changes in the world, changes in lifestyle and the economy, environmental constraints or changes, and uncertainties and risks, according to Bénédicte Aldebert 2008, the tourism sector is a dynamic sector that must adapt to changes.

$>$ A reliable governance platform: the governance of a tourism cluster goes beyond everyday management. It is a business of leadership and animation, but above all the empowerment to act (empowerment). Public policies can not impose on actors what they must do (Zeghni Sylvain, 2012), tourism stakeholders interviewed shed light on the fact that the tourism cluster would play the role of a relevant tool at the level of:

$\checkmark$ The establishment of a reliable and flexible governance platform through concerted management of tourism activities, understood, accepted and verified by all stakeholders, a governance that will evolve with the evolution of the cluster;

$\checkmark$ The introduction of a system for evaluating the evolution of projects launched by the cluster;

$\checkmark$ Supports real clarity and transparency in the practices of cluster members with clear roles, rights and obligations posted;

$\checkmark$ Improving the decision-making process.

> Strong support for sustainable development: stakeholder participation in networks contributes to more sustainable tourism management (Dredge, 2006 in Albrecht, 2013). Networking in the form of a cluster according to the tourism stakeholders interviewed would be a tool for:

$\checkmark$ The elaboration of a clear and respected approach which places the attractiveness of the city of Tangier in a sustainability approach based on unconditional respect for the living conditions of residents and their ecological and social environment;

$\checkmark$ The involvement of all actors in the development process;

$\checkmark$ Easy monitoring of sustainable development practices by different actors.

Based on this analysis, we validate the link between cluster-based cooperation and tourism attractiveness across its three dimensions as shown in the figure below. 


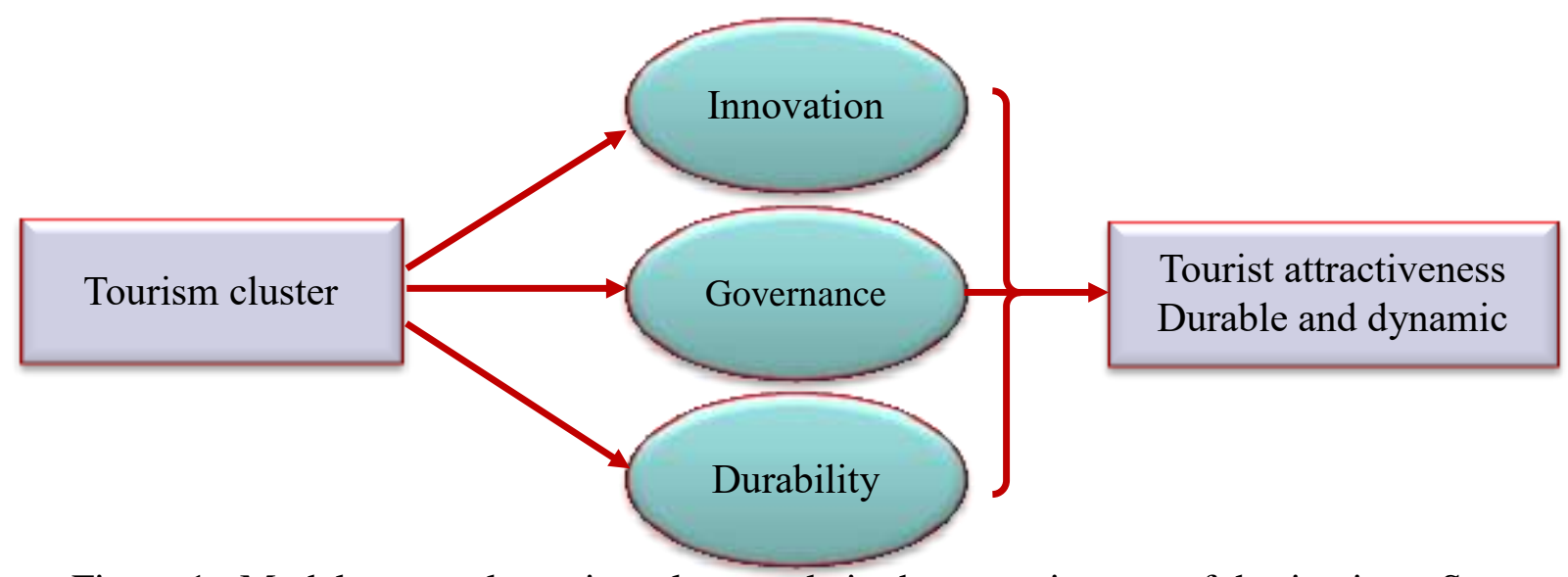

Figure 1 : Model proposal, tourism cluster role in the attractiveness of destinations, Source: Authors

The tourism stakeholders interviewed have also put face some elements that is considered essential for a possible creation of tourism cluster in Tangier, according to them, the tourism cluster must be able to create:

$>$ A climate of trust: which is a missing element in the relations between different tourism stakeholders interviewed in the current state, and which they hope to achieve with cluster creation of which private_actor_5 states: "trust is the key to any form of cooperation".

$>$ Integrated governance in all stages of cluster work. According to private_actor_11, "I do not want anyone to decide for me, I want to participate and be involved in the management of my destination from A to Z. I want to work around a glass table so that nobody has the opportunity nor the chance to get things under the table."

A credible space: simple objectives, measurable, achievable, achievable, within a known time and in reference with the available means. According to private_actor_10, "Clustered cooperation, must not launch us into dreams that will never come true, we must keep a foot on the ground and see things as they are".

The tourism stakeholders interviewed also mentioned the notion of unifying actor, a key player, able to gather and generate all the necessary forces necessary for the development of the cluster, and they insist on the choice of hoteliers to take this responsibility to trigger and to manage the cluster given the key position they occupy in the city's tourist value chain. According to private_actor_7, "we need, a unifying actor of the cluster, capable of attracting other actors, and driving the cluster, an actor directly linked to tourism, for me hoteliers are best placed to this mission ".

\section{Conclusion}

This study is a set of contributions at the same time it provides theoretical, empirical and managerial insight. On the theoretical level, we have proposed a conceptual framework to verify the hypotheses of the impact of the tourism cluster on territorial attractiveness.From an empirical point of view, this study presents two contributions: The first contribution concerns certain essential elements for the success of networking of tourism stakeholders; the tourism cluster according to this study should be able to create a climate of trust, integrated governance, and a credible space of cooperation. So, this study has put face the notion of unifying actor who is a key player, able to generate all the necessary forces necessary for cluster development. This study clearly showed the importance of these notions which is still marginalized in the literature review we consulted.

The second contribution concerns the interdependence of the three dimensions (extracted from the literature) of the tourism cluster role in order to achieve a dynamic and sustainable attractiveness, namely, the dimension related to innovation, the dimension related to governance and the dimension related to sustainable development, the literature review has shed light on different dimensions without making the link between them. 
At the managerial level, our research highlights the main perceptions and expectations of stakeholders by prioritizing them, which can guide decision-makers and tourism managers on the axes, ensuring a better attractiveness of their tourist territory. This study made it possible to identify interesting paths for the creation of an efficient tourism cluster, adapted to the specificities and context of the city of Tangier.

Like any research work, this one presents some limits; it raises the problem of external validity of the research in the sense that our interest has focused on a limited number of actors of tourism. Also, the results from this qualitative study can not be generalized to the mother population.

\section{References}

[1] Albrecht, j. N. (2013). «networking for sustainable tourism - towards a research agenda». Journal of sustainable tourism, 21(5), 639-657.

[2] Cerveaux corinne. Goazen, cluster tourisme du pays basque. Revue espaces, mai-juin 2013, n³12, $\mathrm{p}$ 25-33.

[3] Chabault, d. (2007), m la gouvernance des réseaux territorialises d'organisation: revue de littérature d'un concept émergeant \}, cahiers de recherche du centre d'études et de recherches en management de touraine (cermat).

[4] Clergeau, c. Et violier, p. (2011), « le concept de cluster est-il soluble dans le tourisme ? », conférence intercontinentale en intelligence territoriale.

[5] Clergeau, c. Et violier, p. (2013), « les enjeux particuliers des clusters tourisme », revue espaces tourisme et loisirs, $\mathrm{n}^{\circ} 321$, p. 15-24.

[6] Clergeau cécile (2016). Décloisonnement des clusters de tourisme : perspectives et enjeux. Revue espaces $\mathrm{n}^{\circ} 330$, p.2-4.

[7] Élise, d, (2016), « la coopération intersectorielle, un enjeu pour les clusters de tourisme», revue espaces tourisme et loisirs, $\mathrm{n}^{\circ}$ 330, p. 76. P 81.

[8] Fabry, n. (2009a), « clusters de tourisme, compétitivité des acteurs et attractivité des territoires », revue internationale d'intelligence économique, vol. 1, n 1 , p. 55-66.

[9] Fabry, n. (2009b), « le «cluster touristique»: pertinence du concept et enjeu pour les destinations », sociedad espanola de estudios de la communicacion iberoamericana, $n^{\circ} 20$, p. 13.

[10] Fabry n et zeghni, s. (2013) « cluster tourisme du val d'europe : l'ambition de l'excellence ». Revue espaces, mai-juin, $\mathrm{n}^{\circ} 312$, p.43-48.

[11] Fabry, n. (2012), « l'innovation soutenable dans le tourisme: le cas de la cité européenne dela culture et du tourisme durable (cectd) », management \& avenir, $n^{\circ}$ 6, p. 100-113.

[12] Fabry, n. Et zeghni, s. (2012), « tourisme et développement local : une application aux clusters de tourisme », mondes en développement, vol. 157, $\mathrm{n}^{\circ} 1$, p. 97-110.francois ludovic. Intelligence territoriale: l'intelligence économique appliquée au territoire. Paris : lavoisier, 2008, 121p.

[13] Fererol, me. (2013). Le développement économique en mode marque territoriale : l'exemple du pays basque français. Communication au 50ème colloque de l'asrdlf, université louvain-mons..

[14] Fererol, me. (2013). "cluster tourisme et redynamisation territoriale et touristique, le cas de goazen au pays basque", tourisme et territoire, vol 3 p8, p38.

[15] Forsman m., solitander n. (2003) network knowledge versus cluster knowledge. The gordian knot of knowledge, hanken school of economics, department of management and organisation, entrepreneurship and management, working paper 494, $30 \mathrm{p}$.

[16] Gollub j., hosier a., woo g. (2002) using cluster-based economy strategy to minimize tourism leakages, document de travail, omt, $60 \mathrm{p}$.

[17] Grosseti, m. (2000), les effets de proximité spatiale dans les relations entre organisations: une question d'encastrements, espace et société, $n^{\circ} 101-102$.

[18] Hall, c. M. (2005). Rural wine and food tourism cluster network development. In d. Hall, i. Kirkpatrick, \& m. Mitchell (eds.), rural tourism and sustainable business (pp. 149-164).

[19] Hjalager, a. M. (1997). Innovation patterns in sustainable tourism: an analytical typology. Tourism management, 18(1), 35-41.

[20] Hjalager,a. M. (2002). Repairing innovation defectiveness in tourism. Tourism management, 23(5), 465-474.

[21] Jackson, j., \& murphy, p. (2002). Tourism destinations as clusters: analytical experiences from the new world. Tourism and hospitality research, 4 (1), 36-52. 
[22] Jackson, j., \& murphy, p. (2006). Clusters in regional tourism: an australian case. Annals of tourism research, 33 (4), 1018-1035.

[23] Jackson, j., \& murphy, p. (2002). Tourism destinations as clusters: analytical experiences from the new world. Tourism and hospitality research, 4 (1), 36-52.

[24] Mendez, a. Et messeghem, k. (2009), m introduction \}, management \& avenir, n 5, p. 135-143.

[25] Michael, e.j. (2003), 'tourism micro-clusters, current issues in tourism, vol 4, nos 9 (2), 133-145.

[26] Michael, e.j., (2007), "micro-clusters and networks: the growth of

[27] Tourism", advances in tourism research series.

[28] Nordin, s., (2003), "tourism clustering \& innovation: paths to economic growth and development", mid-sweden university: etour.

[29] Patton, m.1. (1991). "qualitative research on college students: philosophical and methodological comparisons with the quantitative approach", vol 32: 389-396.

[30] Patton, m.c. (1980). "qualitative evaluation methods". London, sage

[31] Porter michael. The competitive advantage of nations. New york : free press, 1990,883p.

[32] Provan, k. G. Et kenis, p. (2008), m modes of network governance: structure, management,and effectiveness \}, journal of public administration research and theory, vol. 18, n 2, p. 229-252.

[33] Yin, r. (1994), "case study research : design and methods (4th revised edition ed.)": sage publications inc.

[34] Yin, r. (2003). "applications of case study research "(2e éd.). London : sage.

[35] Yin, r. (2009), "case study research : design and methods" (4th revised edition ed.): sage publications inc.

[36] Yin, r. K. (2012). “applications of case study research “(3rd ed). Thousand oaks, ca: sage. 